\title{
Gross Pathology Result
}

National Cancer Institute

\section{Source}

National Cancer Institute. Gross Pathology Result. NCI Thesaurus. Code C125008.

The outcome of a gross, or macroscopic, pathologic examination. 